\title{
Treatment Decision-Making of Secondary Prevention After Venous Thromboembolism: Data From the Real-Life START2-POST-VTE Register
}

Clinical and Applied

Thrombosis/Hemostasis

Volume 26: I-8

(C) The Author(s) 2020

Article reuse guidelines:

sagepub.com/journals-permissions DOI: $10.1177 / 1076029620945792$ journals.sagepub.com/home/cat

@SAGE

\author{
Emilia Antonucci, MSc' $\odot$, Ludovica Migliaccio, MTc', \\ Maria Abbattista, $\mathbf{M D}^{2} \odot$, Antonella Caronna, $\mathbf{M D}^{3}$, \\ Sergio De Marchi, $\mathrm{MD}^{4}$, Angela Di Giorgio, $\mathrm{MD}^{5}{ }^{\circ}$, \\ Rosella Di Giulio, $M^{6}{ }^{6}$, Teresa Lerede, $M^{7}$, \\ Maria Grazia Garzia, MD ${ }^{8}$, Ida Martinelli, MD², \\ Daniela Mastroiacovo, MD', Marco Marzolo, $\mathbf{M D}^{10}$, \\ Elisa Montevecchi, MD "', Daniele Pastori, MD ${ }^{12}$, \\ Pasquale Pignatelli, MD ${ }^{12}$, Daniela Poli, MD ${ }^{13}$, Luigi Ria, MD ${ }^{14}$, \\ Angelo Santoliquido, $\mathrm{MD}^{5}$, Sophie Testa, $\mathrm{MD}^{15}$, \\ Gualtiero Palareti, MD', and START POST VTE Investigators
}

\begin{abstract}
Patients with venous thromboembolism (VTE) should receive a decision on the duration of anticoagulant treatment (AT) that is often not easy to make. Sixteen Italian clinical centers included patients with recent VTE in the START2-POST-VTE register and reported the decisions taken on duration of AT in each patient and the reasons for them. At the moment of this report, 472 (66.9\%) of the 705 patients included in the registry were told to stop AT in $59.3 \%$ and to extend it in $40.7 \%$ of patients. Anticoagulant treatment lasted $\geq 3$ months in $>90 \%$ of patients and was extended in patients with proximal deep vein thrombosis because considered at high risk of recurrence or had thrombophilic abnormalities. D-dimer testing, assessment of residual thrombus, and patient preference were also indicated among the criteria influencing the decision. In conclusion, Italian doctors stuck to the minimum 3 months AT after VTE, while the secondary or unprovoked nature of the event was not seen as the prevalent factor influencing AT duration which instead was the result of a complex and multifactorial evaluation of each patient.
\end{abstract}

\section{Keywords}

venous thromboembolism, anticoagulant treatments, duration of anticoagulation, decision, real-life, secondary prevention

Date received: 18 March 2020; revised: 07 July 2020; accepted: 07 July 2020.

\footnotetext{
'Fondazione Arianna Anticoagulazione, Bologna, Italy

${ }^{2}$ Fondazione IRCCS Ca' Granda-Ospedale Maggiore Policlinico, A. Bianchi

Bonomi Hemophilia and Thrombosis Center, Milano, Italy

${ }^{3}$ Medicina Interna d'Urgenza d, Italy

${ }^{4}$ UOC di Angiologia, Azienda Ospedaliero Universitaria Integrata Verona, Italy

${ }^{5}$ UOS Angiologia Columbus, Policlinico Universitario Agostino Gemelli, Università Cattolica del Sacro Cuore, Roma, Italy

${ }^{6}$ U.O. di Medicina Interna A, Ospedale Maggiore, Bologna, Italy

${ }^{7}$ USC SIMT, Centro Emostasi e Trombosi, Ospedale Papa Giovanni XXIII, Bergamo, Italy

${ }^{8}$ UOC Ematologia-Trapianto cellule staminali, Azienda Ospedaliera S.Camillo-Forlanini, Roma, Italy

${ }^{9}$ UOSD Angiologia e Diagnostica Vascolare, Ospedale SS Filippo e Nicola, Avezzano (L'Aquila), Italy
}

\footnotetext{
${ }^{10}$ UOC Medicina Interna, Ospedale di Rovigo, Italy

"' UOC Angiologia dell'Ospedale San Giovanni Apostolo, Castelfranco Veneto, Treviso, Italy

${ }^{12}$ Centro Trombosi, Clinica Medica Policlinico Umberto I, Università la Sapienza Roma, Italy

${ }^{13}$ SOD Malattie Aterotrombotiche, Azienda Ospedaliero UniversitariaCareggi, Firenze

${ }^{14}$ UO Medicina Interna, Presidio Ospedaliero di Gallipoli (Lecce), Italy

${ }^{15}$ UO Laboratorio Analisi, Centro Emostasi e Trombosi A O Istituti Ospitalieri di Cremona, Cremona, Italy
}

Corresponding Author:

Emilia Antonucci, "Arianna Anticoagulazione" Foundation, Via Paolo Fabbri I/3, 40138 Bologna, Italy.

Email: e.antonucci@fondazionearianna.org 


\section{Introduction}

Venous thromboembolism (VTE), which includes deep vein thrombosis (DVT) and/or pulmonary embolism (PE), is a frequent and severe disease whose incidence in developed countries is as high as 1 to 2 per 1000 persons per year. Venous thromboembolism is an acute disease that may have variable early and late outcomes after initial presentation. Patients with acute VTE need immediate active anticoagulant treatment (AT) that is currently performed using different drugs. Guidelines unanimously recommend at least 3 to 6 months to adequately treat the acute episode. ${ }^{1-4}$ An extended treatment may be indicated in some patients to prevent delayed recurrence. Although anticoagulation is highly effective against recurrence, its benefit unfortunately is lost after discontinuation, regardless of duration. ${ }^{5,6}$ Recurrence rate after a first VTE is generally high, with a cumulative incidence after interrupted anticoagulation that may reach $18 \%, 25 \%$, and even $30 \%$ after 2,5 , and 8 years, respectively. ${ }^{7}$

The risk of VTE recurrence is not the same in all patients after a first VTE. Extended anticoagulation beyond the first 3 to 6 months of therapy should be considered in some patients, such as those with unprovoked events or with a persistent risk factor for VTE, because of their high risk of recurrence though not in all patients. Conversely, it is not indicated in patients who may have low risk of recurrence or high risk of bleeding when receiving anticoagulant therapies, thus avoiding the associated risk of bleeding. ${ }^{2}$ The decision on whether to stop anticoagulation after the first 3 to 6 months from the acute event or to extend it indefinitely (with periodical reassessment of patient condition) will depend on carefully assessing the risk of recurrence against that of bleeding. However, estimating the risks of recurrent VTE if AT is discontinued and that of bleeding complications if AT is extended is not an easy task for any treating physician. Recent reports, with data coming from different countries, confirm a wide variability in the practice of physicians as regards AT duration in management of patients with VTE. ${ }^{8,9}$ Although it is relevant to assess to what extent physicians follow the guidelines on this issue, it is also very important to understand how the treating physicians tackle the issue in daily clinical practice; many factors may influence their decision, such as personal experience, confidence in guideline recommendations, and patient characteristics and preferences.

The aim of the START2 POST-VTE register study is to investigate how Italian physicians deal with this issue; in particular, when they take a decision on duration of AT after a recent VTE episode, which decision is taken and why, and what happens during follow-up of the patients. The present analysis examined only the patients who had already received a decision on AT at the moment of analysis.

\section{Materials and Methods}

The START2 Register (Survey on anticoagulated pAtients RegisTer; NCT02219984) is a multicenter, prospective, observational ongoing registry which is described in detail elsewhere. ${ }^{10}$

The START2 POST-VTE is a branch of the START2Register that includes patients with recent VTE episode who have given their written informed consent. Nine thrombosis centers affiliated to the Italian Federation of Anticoagulation Clinics participated in the START2 POST-VTE register, together with 4 centers operating in Angiology departments, 2 centers in departments of Internal Medicine and 1 vascular professional doctor (listed in Appendix A). All the attending physicians were expert vascular doctors.

The patient information was electronically collected in strictly anonymous form in the central database of the registry. The inclusion of patients started in April 2017. At inclusion of each patient physicians participating in the registry were asked to collect: demographic and clinical characteristics, associated risk factors for bleeding and thrombotic complications, routine laboratory data, type, site and clinical aspects of the index VTE episode and time of its occurrence, type of anticoagulant therapy used, and presence of concomitant drugs. Laboratory tests, all optional, were performed by local hospital laboratories. When to take the decision on AT duration was left to the discretion of the attending physicians, who had to declare (a) when they evaluated the patient after index event to decide on duration of AT, (b) what their decision was, and (c) the reasons for the decision. Participating doctors were also asked to follow-up the patients for at least 6 months after the decision was taken.

To evaluate whether and to what extent the presence of comorbid conditions may have influenced the physician's decision to extend anticoagulation or to stop any treatment, we calculated the Charlson's weighted comorbidity index score, that combines both age and comorbidity. ${ }^{11}$ We decided to stratify the weighted comorbidity index into 3 classes: mild, for patients with scores 0 to 1 ; moderate, for patients with scores 2 to 4 ; and severe, for patients with scores $\geq 5$.

\section{Statistical Analysis}

Descriptive analysis was performed. Continuous variables are expressed as median with interquartile range (IQR) or as mean plus or minus standard deviation (SD). Categorical variables are expressed as frequencies and percentages. Preliminary statistical analysis was performed using Wilcoxon signed-rank test (continuous variables) or Fisher exact test (categorical data). A $P$ value $<.05$ was considered statistically significant. Univariate logistic regression analysis was performed to explore the association between the clinical condition and the decision of extending AT. All variables were subsequently entered into a multivariable analysis, and a multiple logistic regression with backward selection was performed to identify the most relevant factors associated with the decision of longer courses of anticoagulation. The results were given as OR with their $95 \%$ CI. A $P<.05$ was considered statistically significant. The SPSS software for Windows, version 25 (SPSS Inc) is used for data processing. 
Table I. Baseline Characteristics of Investigated Patients.

\begin{tabular}{|c|c|}
\hline Patients & $\mathrm{n}=472$ \\
\hline Age at index event, median (IQR) years & $68(52-78)$ \\
\hline$<60$ years, $\%$ & 34.3 \\
\hline $60-69$ years, $\%$ & 21.6 \\
\hline $70-79$ years, $\%$ & 26.1 \\
\hline$\geq 80$ years, $\%$ & 18.0 \\
\hline $\bar{M}$ en, \% & 54.0 \\
\hline \multicolumn{2}{|l|}{ Site of index event, \% } \\
\hline DVT (proximal) & 57.1 \\
\hline $\mathrm{DVT}+\mathrm{PE}$ & 14.4 \\
\hline Isolated PE & 10.8 \\
\hline Isolated distal DVT & 17.7 \\
\hline \multicolumn{2}{|l|}{ Nature of index event } \\
\hline Idiopathic, n (\%) & $237(50.2)$ \\
\hline Secondary, n (\%) & $235(49.8)$ \\
\hline Bed resting ( $>3$ days, within 3 months) & 37.7 \\
\hline Immobilization (within 3 months) & 13.2 \\
\hline Major surgery (within 3 months) & 17.6 \\
\hline Cancer & 12.1 \\
\hline Combined hormonal therapy & 7.8 \\
\hline Chronic inflammatory diseases & 6.2 \\
\hline Laparoscopic surgery & 1.4 \\
\hline Long journey & 0.5 \\
\hline Other & 3.5 \\
\hline \multicolumn{2}{|l|}{ Type of anticoagulant treatment, $\%$} \\
\hline VKA & 7.2 \\
\hline LMWH/Fondaparinux & 11.2 \\
\hline DOACs & 81.6 \\
\hline Apixaban & 27.8 \\
\hline Dabigatran & 12.6 \\
\hline Edoxaban & 13.2 \\
\hline Rivaroxaban & 46.4 \\
\hline \multicolumn{2}{|l|}{ Presence of comorbidities or risk factors, $\%$} \\
\hline None & 58.3 \\
\hline Previous TIA/stroke episode & 3.8 \\
\hline Previous major bleeding episode & 3.8 \\
\hline Hypertension (drug treatment) & 39.1 \\
\hline Diabetes & 9.5 \\
\hline Ischemic heart/peripheral diseases & $3.4 / 1.9$ \\
\hline Heart failure & 1.7 \\
\hline Chronic inflammatory diseases & 4.7 \\
\hline Active cancer & 7.68 \\
\hline Renal function (mL/min, median [IQR]) & $4(62 ; 105)$ \\
\hline Severe renal insufficiency (<30 mL/min) & 1.6 \\
\hline Moderate renal insufficiency $(30-60 \mathrm{~mL} / \mathrm{min})$ & 20.8 \\
\hline Thrombophilic alterations & 17.8 \\
\hline \multicolumn{2}{|l|}{ Evaluated risk of: } \\
\hline \multicolumn{2}{|l|}{ Bleeding, \% } \\
\hline Low/intermediate & 90.5 \\
\hline High & 4.0 \\
\hline Not assessable & 5.5 \\
\hline \multicolumn{2}{|l|}{ Recurrent VTE, \% } \\
\hline Low/intermediate & 70.1 \\
\hline High & 25.3 \\
\hline Not assessable & 4.6 \\
\hline
\end{tabular}

Abbreviations: DOAC, direct oral anticoagulant; DVT, deep venous thrombosis; IQR, interquartile range; LMWH, low-molecular-weight heparin; PE, pulmonary embolism; TIA, transient ischemic attack; VKA, vitamin $\mathrm{K}$ antagonist; VTE, venous thromboembolism.

\section{Results}

\section{Participant Centers and Baseline Patient Characteristics}

At the time of the present analysis (June 30, 2019), 705 patients with VTE were included in the registry. At that moment, 472 $(66.9 \%)$ of them had already received a decision on duration of AT, whereas the remaining 233 patients had not (206 of them were on AT $<180$ days, and 27 for $>180$ ). The present analysis examined only the 472 patients who had received a decision on AT. Their baseline characteristics are shown in Table 1. The median age was 68 years. In about two-thirds of patients, the index VTE episode was proximal DVT, with or without PE, whereas in $20 \%$ it was isolated distal DVT and in $10.8 \%$ of cases isolated PE. The events were considered secondary or idiopathic almost in the same proportion ( $52 \%$ and $48 \%$, respectively). The large majority of patients $(83 \%)$ received a direct oral anticoagulant (DOAC) as anticoagulant drug - in many cases rivaroxaban, the first of these drugs available for this indication in our country-while very few received VKAs $(6 \%)$. A few patients $(7.7 \%)$ also received low-dose acetylsalicylic acid (ASA). The presence of at least one comorbidity or risk factor was frequent in the patients (43.9\%). At inclusion, the physicians were also asked to give an evaluation on the risk of bleeding and recurrent VTE for each patient. These risks were estimated and reported in only $60 \%$ of the patients and were judged to be low/intermediated in the majority of cases $(83.4 \%$ and $67.8 \%$, for bleeding and recurrent events, respectively); however, in a non-negligible portion of patients, the physicians declared they were unable to evaluate these individual risks ( $4.5 \%$ and $7.1 \%$, respectively).

\section{Results of Patient Examination and Decision on Duration of Anticoagulant Treatment}

Table 2 shows the characteristics of the patients recommended to discontinue or extend AT. The time interval from starting AT and the moment of examination was $181 \pm 164$ days (mean \pm SD). In $59.3 \%$ of patients, the decision was to stop anticoagulation. The duration of AT already performed at the time of examination was shorter in these patients than in those in whom the decision was to extend anticoagulation, thus suggesting that in many cases the treating physician had already made up his mind from early treatment. Almost half of patients who discontinued anticoagulation had an index event that was considered idiopathic, and a similar proportion of patients extended treatment with an event that was associated with strong risk factors such as prolonged bed resting, major surgery, and chronic inflammatory disease. Anticoagulation was discontinued in a high proportion of patients with isolated distal DVT. No significant differences were found in the type of anticoagulant drug used and the concomitant antiplatelet treatment. At least one comorbidity or risk factor was equally present in patients who extended or stopped anticoagulation (9.8\% and $9.1 \%$, respectively). Many patients with thrombophilic alterations were recommended to extend anticoagulation. When the Charlson weighted comorbidity index (that included both the presence of comorbidities and ageclasses) was calculated, more patients with a mild risk score 
Table 2. Patients Examined by Treating Physicians and Recommended to Discontinue or Extend Anticoagulant Treatment.

\begin{tabular}{|c|c|c|c|}
\hline & $\begin{array}{l}\text { Patients AC } \\
\text { discontinued, } \\
280(59.3)\end{array}$ & $\begin{array}{l}\text { Patients AC } \\
\text { extended, } \\
192(40.7)\end{array}$ & $P^{\mathrm{a}}$ \\
\hline Age, median (IQR) years & $67(5 \mathrm{I}-78)$ & $69(57-78)$ & \\
\hline $\begin{array}{l}\text { Duration of treatment at the } \\
\text { moment patients were } \\
\text { examined (months, mean } \pm \text { SD) }\end{array}$ & $8 \pm 7.1$ & $11.2 \pm 10.4$ & .0001 \\
\hline$<3$ months $(\%)$ & 8.7 & 9.2 & \\
\hline 3-6 months & 54.5 & 34.4 & .0003 \\
\hline $7-12$ months & 29.3 & 28.1 & \\
\hline$>12$ months & 7.5 & 28.2 & .0001 \\
\hline \multicolumn{4}{|l|}{ Site of index event, \% } \\
\hline Proximal DVT & 53.4 & 60.8 & \\
\hline $\mathrm{DVT}+\mathrm{PE}$ & 11.1 & 17.6 & \\
\hline Isolated PE & 8.4 & 13.2 & .03 \\
\hline Distal DVT & 27.1 & 8.3 & .001 \\
\hline \multicolumn{4}{|l|}{ Nature of index event: } \\
\hline Unprovoked, n (\%) & $129(46.1)$ & $108(56.3)$ & .03 \\
\hline Provoked & $15 \mid(53.9)$ & $84(43.7)$ & \\
\hline $\begin{array}{l}\text { Bed resting (>3 days, within } \\
3 \text { months) }\end{array}$ & 33.1 & 42.3 & \\
\hline $\begin{array}{l}\text { Immobilization (within } 3 \\
\text { months) }\end{array}$ & 25.1 & 0.8 & .001 \\
\hline $\begin{array}{l}\text { Major surgery (within } 3 \\
\text { months) }\end{array}$ & 18.0 & 16.6 & \\
\hline Combined hormonal therapy & 13.0 & 3.2 & .02 \\
\hline Laparoscopic surgery & 0.4 & 2.4 & \\
\hline Long travel & - & 1.0 & \\
\hline \multicolumn{4}{|l|}{ Persisting major factors } \\
\hline Cancer & 6.0 & 18.6 & .003 \\
\hline Chronic inflammatory diseases & 4.4 & 9.8 & \\
\hline Other & - & 5.6 & \\
\hline \multicolumn{4}{|l|}{ Type of anticoagulant treatment, \% } \\
\hline VKA & 5.5 & 8.9 & \\
\hline LMWH/Fondaparinux & 7.8 & 14.6 & \\
\hline DOACs & 86.7 & 76.5 & \\
\hline Apixaban & 21.0 & 26.0 & \\
\hline Dabigatran & 14.6 & 4.2 & \\
\hline Edoxaban & 10.0 & 13.0 & \\
\hline Rivaroxaban & 41.1 & 33.3 & \\
\hline $\begin{array}{l}\text { Concomitant antiplatelet } \\
\text { treatment } \%\end{array}$ & 8.2 & 7.3 & \\
\hline \multicolumn{4}{|l|}{$\begin{array}{l}\text { Presence of comorbidities/risk } \\
\text { factors \% }\end{array}$} \\
\hline None & 60.7 & 54.6 & \\
\hline Previous TIA/stroke episode & 2.1 & 5.2 & \\
\hline $\begin{array}{l}\text { Previous major bleeding } \\
\text { episode }\end{array}$ & 2.5 & 3.1 & \\
\hline Hypertension (drug treatment) & 37.1 & 41.1 & \\
\hline Diabetes & 9.8 & 9.9 & \\
\hline $\begin{array}{l}\text { Ischemic heart/peripheral } \\
\text { diseases }\end{array}$ & $3.2 / 1.1$ & $3.6 / 3.1$ & \\
\hline Heart failure & 1.4 & 2.1 & \\
\hline $\begin{array}{l}\text { Chronic inflammatory } \\
\text { diseases }\end{array}$ & 3.2 & 6.8 & \\
\hline Active cancer & 5.9 & 7.3 & \\
\hline $\begin{array}{l}\text { Renal function }(\mathrm{mL} / \mathrm{min} \text {, } \\
\text { median }[\mathrm{IQR}])\end{array}$ & $\begin{array}{l}84(62.2- \\
\quad \mid 12)\end{array}$ & $\begin{array}{r}84(62.2- \\
105.7)\end{array}$ & \\
\hline
\end{tabular}

Table 2. (continued)

\begin{tabular}{|c|c|c|c|}
\hline & $\begin{array}{c}\text { Patients AC } \\
\text { discontinued, } \\
280(59.3)\end{array}$ & $\begin{array}{c}\text { Patients AC } \\
\text { extended, } \\
192(40.7)\end{array}$ & $P^{\mathrm{a}}$ \\
\hline $\begin{array}{l}\text { Severe renal insufficiency }(<30 \\
\mathrm{mL} / \mathrm{min})(\%)\end{array}$ & 1.7 & 1.5 & \\
\hline $\begin{array}{l}\text { Moderate renal insufficiency } \\
(30-60 \mathrm{~mL})(\%)\end{array}$ & 18.6 & 23.0 & \\
\hline Thrombophilia abnormalities & 13.0 & 22.5 & .008 \\
\hline High risk of bleeding, \% & 7.5 & 0.5 & .002 \\
\hline High risk of recurrent VTE, \% & 8.6 & 42.1 & .0001 \\
\hline \multicolumn{4}{|l|}{$\begin{array}{l}\text { Charlson's weighted comorbidity } \\
\text { index, score }\end{array}$} \\
\hline $0-I$ (mild) & $97(34.6)$ & $47(24.5)$ & .0001 \\
\hline 2-4 (moderate) & $100(35.7)$ & $87(45.3)$ & .004 \\
\hline$\geq 5$ (severe) & $83(29.6)$ & $58(30.2)$ & \\
\hline
\end{tabular}

Abbreviations: AC, anticoagulation treatment; DOAC, direct oral anticoagulant; DVT, deep venous thrombosis; LMWH, low-molecular weight heparin; $\mathrm{PE}$, pulmonary embolism; TIA, transient ischemic attack; VKA, vitamin $\mathrm{K}$ antagonist; VTE, venous thromboembolism.

${ }^{a}$ Only significant results are shown.

(0-1 factor) discontinued anticoagulation $(P=.0001)$, whereas more patients with moderate score (2-4 factors) extended therapy. As expected, high bleeding or recurrence risks were closely associated with discontinuation or extension of AT, respectively.

At the moment of examination or shortly before, only a few patients were recommended to perform tests, including D-dimer testing, compression ultrasonography of deep leg veins $(46.5 \%$ of patients with DVT), echocardiography, and/or pulmonary perfusion scintigraphy ( $26 \%$ and $4 \%$ of patients with $\mathrm{PE}$, respectively).

To identify the most relevant factors associated with the decision of longer courses of anticoagulation, a univariate analysis was performed. Subsequently, a multivariate analysis with backward selection showed that thrombophilia abnormalities, proximal DVT as index event and evaluation of high recurrence risk were independently associated with the decision of extending AT, whereas isolated distal DVT as index event was a factor associated with a decision to discontinue AT (Table 3).

\section{What Physicians Declared About the Reason/s for the Decision}

Table 4 shows the reasons put forward by physicians to support their decision on discontinuation (Table 4A) or extension (Table 4B) of anticoagulation treatment. In most cases (almost $82 \%$ of patients), the decision to stop anticoagulation was laid out at the beginning of AT. In almost one-third of patients, the risk of recurrence was considered so low as to discourage treatment extension. Physician or patient preference to stop AT was also taken into account (altogether about $28 \%$ of cases). Less frequently, the risk of bleeding complications was reported as a reason for withdrawing AT. In less than one-fourth of patients, a different antithrombotic treatment was suggested after the standard AT was stopped (including sulodexide or ASA). 
Table 3. Factors Associated With Longer Courses of Anticoagulation: Univariate and Multivariate Logistic Analysis.

\begin{tabular}{|c|c|c|c|c|c|c|}
\hline \multirow[b]{2}{*}{ Factors } & \multicolumn{3}{|c|}{ Univariate } & \multicolumn{3}{|c|}{ Multivariate } \\
\hline & OR & $95 \% \mathrm{Cl}$ & $P$ & OR & $95 \% \mathrm{Cl}$ & $P$ \\
\hline $\mathrm{Age}^{\mathrm{a}}$ & I.7 & $0.90-2.0$ & .07 & 2.1 & $0.80-5.8$ & .1 \\
\hline $\begin{array}{l}\text { Thrombophilia } \\
\text { abnormalities }\end{array}$ & 2.5 & I.4-5.I & .002 & 2.5 & $1.3-4.7$ & .003 \\
\hline Unprovoked event & 1.8 & $1.1-6.2$ & .01 & 1.5 & $0.61-4.6$ & .3 \\
\hline Proximal DVT & 2.1 & $1.3-4.1$ & .03 & $\mathrm{I} .8$ & $1.1-3.2$ & .04 \\
\hline Distal DVT & 0.7 & $0.58-0.79$ & .01 & 0.2 & $0.72-0.82$ & .02 \\
\hline Isolated PE & 2.8 & I.5-5.4 & .02 & 2.6 & $0.85-7.8$ & .06 \\
\hline 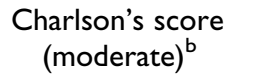 & 1.7 & $1.2-6.3$ & .05 & 1.7 & $0.58-4.9$ & .3 \\
\hline $\begin{array}{l}\text { High risk of VTE } \\
\text { recurrence }{ }^{c}\end{array}$ & 2.8 & I.3-5.I & .01 & 2.2 & I.I-4.6 & .04 \\
\hline
\end{tabular}

Abbreviations: DVT, deep vein thrombosis; PE, pulmonary embolism; VTE, venous thromboembolism.

${ }^{\text {a } A g e}$ is considered as continuous variable.

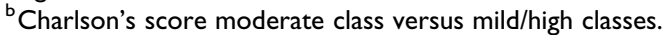

${ }^{\mathrm{c}}$ Individual thrombotic risk assessment of patients formulated by the treating physicians.

Table 4 reasons given by treating physicians to support discontinuation (A) or extension (B) of anticoagulation treatment (more than one reason may have been attributed to the same patient).

The most frequent condition leading to AT extension (Panel B) was the unprovoked nature of the index event, followed by the presence of residual vein thrombosis and the fact that the event was a recurrent VTE. In general, AT was extended by using the same drug as before; however, in 26 patients receiving apixaban (about one-third of those who were treated with this DOAC), the dose was reduced from 5 to $2.5 \mathrm{mg}$, twice daily.

The attending physicians were also asked to choose among prespecified general criteria they often used to inform their decision. Only one participant said he followed the recommendations of the ACCP guidelines. ${ }^{2}$ The majority of participants $(45 \%)$ chose the global term "Management" as a general criterion adopted, which included personal and clinical characteristics of the patient, results of objective tests (especially Compression UltraSonography), laboratory tests (especially D-dimer and thrombophilia assays), and assessment of individual bleeding and thrombotic risks. Many participants (30\%) said they used D-dimer assay after anticoagulation was temporarily stopped to decide whether to definitively stop or resume anticoagulation. Very few participants (4\%) used one of the available predictive scores (DASH, Vienna or Khorana scores). A significant proportion of participants (about 20\%) refused to declare the prevalent criterion for their decision.

\section{Discussion}

Starting on April 2017, the START POST-VTE registry included patients with a recent VTE episode, focusing in particular on the decisions taken by their treating physicians
Table 4. Reasons Given by Treating Physicians to Support Discontinuation (A) or Extension (B) of Anticoagulation Treatment (More Than One Reason May Have Been Attributed to the Same Patient).

\begin{tabular}{lc}
\hline A. Discontinuation & \\
\hline Total patients, n (\%) & 280 \\
Males & $137(49.2)$ \\
Age years, median (IQR) & $67(5 \mathrm{I}-78)$ \\
End of the planned treatment period & $229(81.8)$ \\
Low risk of recurrence & $8 \mathrm{I}(28.9)$ \\
Treating physician's preference & $49(17.5)$ \\
Negative d-dimer procedure & $45(16.1)$ \\
Patient preference & $30(10.7)$ \\
High bleeding risk & $21(7.5)$ \\
Tendency to fall & $1 \mathrm{I}(3.9)$ \\
Presence of contraindications to extended treatment & $10(3.6)$ \\
Use of a predictive score & $9(3.2)$ \\
Major bleeding event (previous or during & $4(1.4)$ \\
$\quad$ anticoagulation) & \\
Patient moved to another place & $3(1.2$ \\
Lost to follow-up & $1(0.4)$ \\
Patients addressed to a different drug treatment, $\mathrm{n}(\%)$ & $64(22.8)$ \\
$\quad$ ASA I00 mg & 14 \\
Sulodexide & 50 \\
B. Extension & \\
\hline
\end{tabular}

Total patients, n (\%) 198

Males $117(60.9)$

Age years, median (IQR)

Unprovoked index event was

$69(57-78)$

$40(20.8)$

Recurrent VTE

Low bleeding risk

$37(19.3)$

$36(18.7)$

Positive D-dimer

$34(17.7)$

$17(8.8)$

$16(8.3)$

$16(8.3)$

$15(7.8)$

$13(6.8)$

II (5.7)

II (5.7)

7 (3.6)

$5(2.6)$

I (0.5)

I (0.5)

Pulmonary hypertension

Treatment prescribed for extended anticoagulation

VKA

LMWH/Fondaparinux

Apixaban $5 \mathrm{mg}$ BID

Apixaban $2.5 \mathrm{mg}$ BID

Dabigatran $150 \mathrm{mg}$ BID

Edoxaban $60 \mathrm{mg}$ OID

Rivaroxaban $20 \mathrm{mg}$ OID

Abbreviations: IQR, interquartile range; VTE, venous thromboembolism.

regarding anticoagulation duration, and the reasons guiding those decisions. More than $80 \%$ of the included patients were treated with a DOAC, whereas only $6 \%$ received a VKA, thus proving that most Italian doctors currently prefer DOACs over VKAs for acute and long-term treatment of patients with VTE. International guidelines recommend that patients with acute 
VTE should receive AT for no less than 3 months. ${ }^{2}$ The results in our cohort are in line with this recommendation, since very few patients (7.2\%), mainly those presenting with isolated distal DVT, stopped anticoagulation within 3 months of treatment. The achieved adherence to not less than 3 months duration of AT as recommended by guidelines should be underlined, since a high prevalence of patients receiving AT for less than 3 months (involving more than $20 \%$ of the investigated patients) is reported in the literature. ${ }^{12,13}$

The decision on AT duration was taken at a median time of $181 \pm 164$ days from inclusion in the registry and was to stop AT in $59.3 \%$ of patients. This timing for the decision may look somewhat late since it might rather have been expected 3 months after AT. However, we are convinced that it represents the practice of most Italian physicians who deem 6 months AT as minimum duration after a VTE event. Furthermore, it does not go against international guidelines, since they unanimously recommend "no less" than 3 months ${ }^{2,4}$ or more explicitly, 3 to 6 months for long-term treatment. ${ }^{3}$ It is interesting to note, however, that $40 \%$ of patients who discontinued anticoagulation did so after 6 months of the index event and at least 2 factors, in our view, may have contributed to this: first, as mentioned before, many Italian doctors are convinced that patients with VTE need to receive about 6 months of AT, though its prolongation, albeit of little benefit, cannot do any harm; second, our national health service does not explicitly recommend or support the practice of reexamining all patients 3 to 6 months after a VTE episode and so treatment may continue beyond that period.

The present study showed that $40.7 \%$ of patients were recommended to extend anticoagulation; more than $50 \%$ of them were notified when AT had already lasted $>6$ months, thus indicating that the physicians had already made up their minds to extend AT and were not particularly waiting for feedback after 3 to 6 months of therapy.

Current international guidelines suggest an extended AT in patients with unprovoked events, ${ }^{2}$ or when the risk of recurrent events is classified as intermediate or high, ${ }^{4}$ provided that the risk of bleeding complications is not high. Conversely, an important part of our patient cohort (43.7\%), in whom AT was extended, had an index VTE event that was provoked, whereas treatment was discontinued in a similar proportion (46.1\%) of patients whose event was idiopathic. These findings show that our participating doctors do not deem the provoked or unprovoked nature of the event as the only or even prevalent factor for deciding on duration of anticoagulation. Recent important scientific reports support this view. In the EINSTEIN CHOICE study, assessing the efficacy and safety of rivaroxaban (at standard or reduced daily dose) or aspirin use for extended treatment, more than half of all included patients had provoked VTE events. ${ }^{14} \mathrm{~A}$ recent study analyzing the risk of recurrent VTE according to baseline risk factor profiles concluded that "Recurrence rates in patients with VTE provoked by minor persistent or minor transient risk factors were not significantly lower than that with unprovoked VTE. Therefore, such patients may also benefit from extended anticoagulation therapy."15 Recent results of data from a nationwide Danish cohort showed that the long-term (10 years) cumulative risk of recurrent VTE was not much lower after provoked (about $16 \%$ ) versus unprovoked (about $20 \%$ ) events. ${ }^{16}$ Finally, in a recent commentary, distinguished colleagues recommended stopping "dichotomizing" VTE events as provoked or unprovoked. ${ }^{17}$

Although - in our results - age was not a criterion for preferring 1 of the 2 treatment options, other patient and/or event characteristics have influenced the decision on AT duration, as shown by the multivariate regression analysis. As expected, patients with distal DVT more frequently stopped AT. Conversely, AT was preferentially extended when the index event was a proximal DVT, when risk of recurrent events was judged to be high, when thrombophilic alterations were present. In line with what some clinical studies have suggested, ${ }^{18-20}$ one-third of all investigators used D-dimer testing to assess the risk of recurrent events and help inform decision on duration of anticoagulation. However, the general impression is that the participant physicians used the results of D-dimer testing not as single criterion for the decision; they mainly evaluated the results in the context of other patient and/or event characteristics. In contrast, clinical prediction rules were seldom used by investigators to help in their decision. The presence of residual vein thrombosis was a condition reported in about $20 \%$ of patients referred for extended AT; this was in line with many scientific data pointing to a relationship between the persistence of a residual thrombus and an increased risk of thrombosis recurrence. ${ }^{21-23}$

On the basis of positive results of clinical trials, ${ }^{24,25}$ the attending physicians suggested to about one-fourth of the patients who discontinued AT to assume sulodexide or aspirin as a substitute treatment in the months that followed. In some patients, the therapy for extended treatment was shifted from full- to low-dose apixaban; this was supported by results obtained in the Amplify-Extension trial ${ }^{26}$ in which low-dose apixaban (2.5 $\mathrm{mg}$ twice daily) proved equally effective as and safer than standard dose (5 mg twice daily) for extended treatment, while in all the remaining cases the original AT was maintained also for extended therapy. It should be noted, however, that the EINSTEIN CHOICE trial ${ }^{14}$ showing a similar advantageous use of low-dose rivaroxaban for extended treatment had only just been published at the time of the present cohort study and so its results had not yet been introduced into clinical practice.

Deriving from the everyday clinical practice of Italian vascular doctors, our results show that the decision on duration of AT in patients with VTE is an uneasy and complex task for them. The final decision may be influenced by a wide variety of factors and determinants that make it much more complicated than sticking to the simple dualism between provoked or unprovoked events. In that sense, it can be said that the participating treating physicians only partially follow the guideline indications. Two recent, survey-based studies, performed in different geographic context (Australia and Northern Europe), have investigated the physician's attitude to adhere to the guideline indications. ${ }^{8,9}$ Although in both studies most physicians said they followed the guideline indications on the issue (very likely, even our Italian physicians would have given the same answer if asked), both studies showed a considerable variability 
in VTE management practices, in a way similar to what we found in our study. In particular, the difficulty in assessing the individual patient risk of developing a major bleeding complication during AT was underlined in the study by de Winter et $\mathrm{al}^{9}$ as well as in the present study.

In conclusion, when dealing with patients after a VTE episode, the Italian vascular doctors involved in the present study generally stuck to the minimum 3-month period of AT recommended by international guidelines. The treating physicians made a decision to stop or extend AT that was not greatly affected by whether the index event was secondary or unprovoked. This result may be attributed to their evaluation of the etiology of the event (secondary or unprovoked) as part of a series of many other factors, including the individual clinical conditions of patients and presence of risk factors for either bleeding or thrombosis. Although doctors in many patients seemed to have already formed an opinion on the duration of anticoagulation at the beginning of treatment, in many cases the use of laboratory tests (ie, D-dimer) and/or CUS examinations have guided their choice on duration of AT.

\section{Appendix A}

List of participating centers and investigators who contributed to the START2 POST-VTE Registry

- Benilde Cosmi, Ludovica Migliaccio, UO di Angiologia e Malattie Coagulazione, AOU S. Orsola-Malpighi, Bologna, Bologna

- Antonella Caronna, Luca Sarti, Medicina Interna d’Urgenza Nuovo Ospedale Civile S. Agostino Estense, Modena

- Antonio Chistolini, Alessandra Serrao, Sezione Ematologia, Dipartimento di Biotecnologie Cellulari ed Ematologia Azienda Ospedaliero Universitaria Policlinico Umberto I, Roma

- Rosella Di Giulio, U.O. di Medicina Interna A, Ospedale Maggiore, Bologna

- Anna Falanga, Teresa Lerede; Università Bicocca Milano, Dept. Medicine and Surgery, Monza and USC SIMT, Centro Emostasi e Trombosi, Ospedale Papa Giovanni XXIII, Bergamo

- Maria Grazia Garzia, UOC Ematologia-Trapianto cellule staminali, Azienda Ospedaliera S.CamilloForlanini, Roma

- Elvira Grandone, Donatella Colaizzo, Centro Trombosi, Casa del Sollievo e della Sofferenza, S.Giovanni Rotondo (Foggia)

- Maria Granito, Maria Rosaria Veropalumbo S.C. Medicina Cardiovascolare, Arcispedale Santa Maria Nuova, Reggio Emilia

- Gianfranco Lessiani, Ambulatorio Vascolare, UOC Medicina Cardiologica, Ospedale Villa Serena Città Sant'Angelo, Pescara

- Ida Martinelli, Maria Abbattista, UOS Malattie Trombotiche, U.O.C. Medicina Generale, Fondazione IRCSS
Ca Granda, Ospedale Maggiore Università degli studi di Milano

- Daniela Mastroiacovo, UOSD Angiologia e Diagnostica Vascolare, Ospedale SS Filippo e Nicola, Avezzano (L’Aquila)

- Marco Marzolo, UOC Medicina Interna, Ospedale di Rovigo

- Roberto Parisi, UOSD Ipertensione e Patologie Endocrine Metaboliche Angiologiche, Ospedale SS. Giovanni e Paolo, Venezia

- Pasquale Pignatelli, Daniele Pastori, Centro Trombosi, Clinica Medica Policlinico Umberto $\mathrm{I}^{\circ}$, Università la Sapienza Roma

- Daniela Poli, Lucia Martinese, Elisa Vignini, Eleonora Camilleri, SOD Malattie Aterotrombotiche, Azienda Ospedaliero Universitaria-Careggi, Firenze

- Manlio Prior, Sergio De Marchi, Anna Maria Rigoni UOC di Angiologia, Azienda Ospedaliero Universitaria Integrata Verona

- Luigi Ria, UO Medicina Interna, Presidio Ospedaliero di Gallipoli (Lecce)

- Angelo Santoliquido Angela Di Giorgio UOS Angiologia Columbus, Policlinico Universitario Agostino Gemelli, Università Cattolica del Sacro Cuore, Roma

- Piera Sivera, S.C.D.U. EMATOLOGIA Azienda Ospedaliera Ordine Mauriziano, Torino

- Sophie Testa, Oriana Paoletti, UO Laboratorio Analisi, Centro Emostasi e Trombosi A O Istituti Ospitalieri di Cremona, Cremona

- Adriana Visonà, Elisa Montevecchi, UOC Angiologia dell'Ospedale San Giovanni Apostolo, Castelfranco Veneto, Treviso

\section{Authors' Note}

Clinical Trial Registration-URL: http://www.clinicaltrials.gov. Unique identifier: NCT02219984.

\section{Acknowledgment}

The authors thank Dr Stephen Jewkes for his revision of the English.

\section{Declaration of Conflicting Interests}

The author(s) declared no potential conflicts of interest with respect to the research, authorship, and/or publication of this article.

\section{Funding}

The author(s) disclosed receipt of the following financial support for the research, authorship, and/or publication of this article: The Arianna Anticoagulation Foundation promotes and supports the START2 Registry, including the present study; the Foundation received a grant from Alfasigma company (Bologna, Italy) dedicated to the START2-POST-VTE registry.

\section{ORCID iD}

Emilia Antonucci (D) https://orcid.org/0000-0001-9185-2046

Maria Abbattista (D) https://orcid.org/0000-0003-3620-3347

Angela Di Giorgio (D) https://orcid.org/0000-0003-4622-6999 


\section{References}

1. Boutitie F, Pinede L, Schulman S, et al. Influence of preceding length of anticoagulant treatment and initial presentation of venous thromboembolism on risk of recurrence after stopping treatment: analysis of individual participants' data from seven trials. BMJ. 2011;342:d3036.

2. Kearon C, Akl EA, Ornelas J, et al. Antithrombotic therapy for VTE disease: CHEST guideline and expert panel report. Chest. 2016;149(2):315-352.

3. Mazzolai L, Aboyans V, Ageno W, et al. Diagnosis and management of acute deep vein thrombosis: a joint consensus document from the European Society of Cardiology working groups of aorta and peripheral vascular diseases and pulmonary circulation and right ventricular function. Eur Heart J. 2018;39(47): 4208-4218.

4. Konstantinides SV, Meyer G, Becattini C, et al. 2019 ESC Guidelines for the diagnosis and management of acute pulmonary embolism developed in collaboration with the European Respiratory Society (ERS): the task force for the diagnosis and management of acute pulmonary embolism of the European society of cardiology (ESC). Eur Respir J. 2019;54(3):1901647.

5. Agnelli G, Prandoni P, Santamaria MG, et al. Three months versus one year of oral anticoagulant therapy for idiopathic deep venous thrombosis. N Engl J Med. 2001;345(3):165-169.

6. Couturaud F, Sanchez O, Pernod G, et al. Six months vs extended oral anticoagulation after a first episode of pulmonary embolism: the PADIS-PE randomized clinical trial. JAMA. 2015;314(1): 31-40.

7. Prandoni P, Lensing AWA, Cogo A, et al. The long-term clinical course of acute deep venous thrombosis. Ann Intern Med. 1996; 125(1):1-7.

8. Wallace R, Anderson MA, See K, Gorelik A, Irving L, Manser R. Venous thromboembolism management practices and knowledge of guidelines: a survey of Australian haematologists and respiratory physicians. Intern Med J. 2017;47(4):436-446.

9. de Winter MA, Remme GCP, Kaasjager K, Nijkeuter M. Shortterm versus extended anticoagulant treatment for unprovoked venous thromboembolism: a survey on guideline adherence and physicians' considerations. Thromb Res. 2019;183:49-55.

10. Antonucci E, Poli D, Tosetto A, et al. The Italian START-register on anticoagulation with focus on atrial fibrillation. PLoS One. 2015;10(5):e0124719.

11. Charlson ME, Pompei P, Ales KL, MacKenzie CR. A new method of classifying prognostic comorbidity in longitudinal studies: development and validation. J Chronic Dis. 1987;40(5):373-383.

12. Ganz DA, Glynn RJ, Mogun H, Knight EL, Bohn RL, Avorn J. Adherence to guidelines for oral anticoagulation after venous thrombosis and pulmonary embolism. J Gen Intern Med. 2000; 15(11):776-781.
13. Kaatz S, Fu AC, AbuDagga A, et al. Association between anticoagulant treatment duration and risk of venous thromboembolism recurrence and bleeding in clinical practice. Thromb Res. 2014; 134(4):807-813.

14. Weitz JI, Lensing AWA, Prins MH, et al. Rivaroxaban or aspirin for extended treatment of venous thromboembolism. $N$ Engl $J$ Med. 2017;376(13):1211-1222.

15. Prins MH, Lensing AWA, Prandoni $\mathrm{P}$, et al. Risk of recurrent venous thromboembolism according to baseline risk factor profiles. Blood Adv. 2018;2(7):788-796.

16. Albertsen IE, Nielsen PB, Sogaard M, et al. Risk of recurrent venous thromboembolism: a Danish Nationwide Cohort Study. Am J Med. 2018;131(9):1067-1074. e4.

17. lbertsen IE, Piazza G, Goldhaber SZ. Let's stop dichotomizing venous thromboembolism as provoked or unprovoked. Circulation. 2018;138(23):2591-2593.

18. Palareti G, Cosmi B, Legnani C, et al. D-dimer testing to determine the duration of anticoagulation therapy. N Engl J Med. 2006; 355(17):1780-1789.

19. Douketis J, Tosetto A, Marcucci M, et al. Patient-level metaanalysis: effect of measurement timing, threshold, and patient age on ability of D-dimer testing to assess recurrence risk after unprovoked venous thromboembolism. Ann Intern Med. 2010;153(8): 523-531.

20. Palareti G, Cosmi B, Legnani C, et al. D-dimer to guide the duration of anticoagulation in patients with venous thromboembolism: a management study. Blood. 2014;124(2):196-203.

21. Mazetto BM, Orsi FLA, Silveira SAF, et al. Residual vein thrombosis echogenicity is associated to the risk of DVT recurrence: a cohort study. Clin Appl Thromb Hemost. 2018;24(3):477-482.

22. Prandoni P, Prins MH, Lensing AW, et al. Residual thrombosis on ultrasonography to guide the duration of anticoagulation in patients with deep venous thrombosis: a randomized trial. Ann Intern Med. 2009;150(9):577-585.

23. Prandoni P, Vedovetto V, Ciammaichella M, et al. Residual vein thrombosis and serial D-dimer for the long-term management of patients with deep venous thrombosis. Thromb Res. 2017;154: $35-41$.

24. Andreozzi GM, Bignamini AA, Davi G, et al. Sulodexide for the prevention of recurrent venous thromboembolism: the sulodexide in secondary prevention of recurrent deep vein thrombosis (SURVET) study: a multicenter, randomized, double-blind, placebo-controlled trial. Circulation. 2015; 132(20):1891-1897.

25. Simes J, Becattini C, Agnelli G, et al. Aspirin for the prevention of recurrent venous thromboembolism: the INSPIRE collaboration. Circulation. 2014;130(13):1062-1067.

26. Agnelli G, Buller HR, Cohen A, et al. Apixaban for extended treatment of venous thromboembolism. N Engl J Med. 2013; 368(8):699-708. 